\title{
El presupuesto, el Estado y la nación en el Perú decimonónico y la corrupción institucionalizada, 1823-1879
}

Miriam Salas Olivari (2016). Lima: Instituto de Estudios Histórico-Marítimos del Perú, $713 \mathrm{pp}$.

Un área descuidada de la historiografía nacional está relacionada con los estudios sobre la gestación del Estado moderno, su desarrollo y la evolución de sus instituciones administrativas, por ello la obra de la historiadora Miriam Salas es un esfuerzo notable por cubrir esta área inconclusa de nuestra historia republicana. Un libro importante que en el contexto del bicentenario y la coyuntura actual, es más que pertinente desatacar, así como resaltar los aspectos que aborda como: el perfeccionamiento de herramientas como el presupuesto para la administración pública, la delimitación de las funciones del Ministerio de Hacienda y el análisis de la corrupción como un problema estructural para la buena administración de lo público en la joven república peruana.

El libro está dividido en dos partes y comprende 13 capítulos. Y es una detallada exploración de la evolución del "presupuesto nacional» durante el período 1823-1879. La primera parte, nos ofrece un detallado recuento de las etapas por la que atraviesa el presupuesto desde el inicio de la República hasta alcanzar su primera organicidad a través de la «Ley del presupuesto de 1879-1880». Se identifican para el período 1823-1878 seis etapas a los que la autora denomina «momentos» divididos de la siguiente manera: 1) $1823-1840,2) 1840-1860,3) 1862-1869$, 4) $1869-1872$, 5) $1872-1876$ y 6) 18761878. La segunda parte, se concentra en explorar la Ley de Presupuesto de 1879-1880, así como los diversos «tipos de presupuestos» que dicha norma contemplaba como lo fueron: presupuesto «ordinario», presupuesto «ordinario adicional», presupuesto "extraordinario» y presupuesto "extraordinario adicional».

Hay algunos presupuestos básicos que debemos tener presentes para evaluar lo hecho en este período a nivel de organización del Estado, desarrollo de instituciones de gestión de lo público ${ }^{1}$ y herramientas da carácter administrativo, pues la lectura desde el presente de este período nos puede llevar a pasar por alto o subestimar ciertos avances positivos en la construcción del Estado y el desarrollo de sus diferentes instituciones. Durante los primeros veinticinco años de la República (1821-1846) «no se planificó el ingreso, ni menos se controló su gasto» porque «el desarrollo del Estado y el gasto pú-

1 Desde finales de los ańos noventa de la centuria pasada e inicios de esta el tema de la gestión pública ha empezado a calar entre los investigadores sociales, desarrollándose una nutrida bibliografía que empieza a hacer un análisis retrospectivo del desarrollo de las instituciones de la administración pública en términos históricos, alejándose de los tecnicismos administrativos. Por ello, con la finalidad de no caer en anacronismos y usos poco convenientes de términos modernos, nos referimos a los trabajos de este corte como de «historia de la gestión de lo público», entendiendo que los estados, desde sus orígenes busca dar solución a los problemas que conlleva la administración de determinados servicios hacia la sociedad y que con el paso del tiempo aumentan o se delimitan mejor, por las crecientes necesidades del Estado para su supervivencia y atender las demandas sociales. 
blico corrían a cargo de la voluntad y los deseos del caudillo de turno, y en ese sentido, los gastos militares consumían el grueso de los ingresos» (p. 29). En este escenario es interesante notar como el Ministerio de Guerra, posteriormente Ministerio de Guerra y Marina, mantuvo una presencia significativa y absorbía una importante cantidad del gasto para el mantenimiento de los pertrechos militares y el salario de los oficiales. Gradualmente en atención a necesidades específicas del Estado es que se tiene que reorientar el gasto público y crear instituciones de carácter más técnico y que cubran determinadas demandas sociales. La Constitución como mecanismo formal estableció las pautas administrativas y políticas, para perfilar las funciones de las instituciones públicas y los elementos procedimentales para la fijación del presupuesto, pero fue un proceso gradual. El poder de los caudillos era demasiado amplio como para que la constitución pudiera cumplirse a cabalidad pero gradualmente moldeaba la estructura del Estado. A medida que el Estado se afianza comienzan a aparecer nuevos actores que obligan al Estado a perfeccionar sus herramientas administrativas, aunque sea formalmente, para dar luego lugar a cambios reales. En esta línea se construyen relaciones tensas entre los miembros de la elite, aparecen nuevos grupos de presión al Estado como la burocracia, la movilización social, y la intelectualidad, que ponen en cuestión el orden tradicional caudillista. Como acertadamente señala Salas, el papel de los civiles fue invisibilizado por la historiografía nacional al centrarse en la figura de los caudillos, sin embargo, se aprecia «a la antigua elite como el cerebro que desde la elaboración de las diferentes constituciones moldearon la estructura del Estado y el destino de la nación peruana». Su presencia, a decir de la autora, «como legitimadores del poder les permitió participar casi en exclusividad en alianza con la fuerza de las armas de las mieles» (p. 669) en el diseño del Estado, el aparato burocrático y las herramientas de gestión administrativas.

El período 1825-1840, está marcado por la búsqueda del diseńo constitucional y la ausencia de presupuesto. La Constitución de 1823 fijó como ente responsable de la elaboración del presupuesto al Ministerio de Hacienda, «quien debía presentar anualmente al Congreso: los planes orgánicos de Hacienda en general y de sus oficina en particular; el presupuesto de los gastos precisos para el servicio de la República, y, el plan de contribuciones ordinarias para cubrir ese gasto, y, el de las extraordinarias para satisfacer los empréstitos nacionales y sus réditos correspondientes (p. 28). La Constitución de 1826 por su parte, de carácter presidencialista, "colocó al Ministerio de Hacienda bajo la autoridad del presidente, mientras que en paralelo no creyó en la necesidad de un presupuesto sino que cada secretaría formule su propio presupuesto (p. 29). Con un diseño tan poco claro para llevar las cuentas del Estado «la pobreza generalizada obligó a los gobiernos caudillistas a reimplantar el tributo y la esclavitud para salvar las arcas fiscales y los campos de cultivo de la costa» (p. 20).

El período 1840-1860, tiene como característica el gran crecimiento económico generado por el guano y el endeudamiento del país. Por ello, se hizo necesario establecer 
un sistema administrativo más coherente y eficiente, es así que surge el primer intento formal de crear un presupuesto público. Presentándose muchos problemas de carácter técnico e inexactitudes. El Proyecto de Presupuesto de 1846, adolecía de un mal diseño pues «en el resumen publicado en El Peruano se situó el ingreso anual en 5961639 pesos y los egresos en 4191800 , peor en el propio oficio de remisión al Ministro seńalaba que los ingresos no llegaban a sumar los cuatro millones de pesos, y «que por otra lado no se incluyó en los egresos parte de los sueldos devengados por los empleados públicos y pensiones de civiles y militares, como tampoco los gastos generados por la Tesorería de Lima, la deuda con Colombia y Chile, los saldos de la guerra civil y otros gastos sin cubrir». El ramo de hacienda experimentó un engrosamiento del gasto, ello debido a la mala gestión administrativa desde el mismo Ejecutivo. Como nos recuerda la autora «el gobierno de Echenique justificaba las operaciones de la deuda pública con el argumento de que se reducían los intereses del $6 \%$ al $4 \%$ de acuerdo a la ley de la Consolidación" (p. 39). Es ahí donde se hacen oír algunas voces alertas a la ahora visible corrupción enquistada en el poder, Domingo Elías, uno de los hombres más ricos de aquel entonces, «envió cartas públicas ${ }^{2}$ al presidente Echenique, denunciando este escándalo financiero» que concluiría con el golpe de Estado propinado por Castilla a Echenique (p.3 9).

Para el período 1862-1869, no encontramos la promulgación de ningún presupuesto hasta 1861. El carácter provisional del gobierno de Castilla de 1858 a 1861, impidió que se promulgase un presupuesto antes. En el presupuesto de 1861-1862 los ingresos se incrementaron hasta alcanzar los 20763035 pesos y en contraposición los egresos fueron de 16456018 pesos. El boom guanero originó un clima de mayor atención a los temas fiscales entre la aún incipiente sociedad civil, así como propició la "unión entre capital comercial y el financiero" que dio lugar a los primeros bancos con capital nativo, y emisión periódica de material contable y estadístico oficial. Aparecieron en este período los textos de Manuel Atanasio Fuentes La estadística general de Lima (1858) y Cuestiones civiles. I. Apuntes sobre los registros del estado civil y la necesidad de organizarlos en el Perú (1868), en 1862 apareció el Mercurio como diario comercial y político, por decreto de 1855 el gobierno ordenó levantar «una carta geográfica de la República y la topografía de sus límites con el Ecuador y con Bolivia y otros puntos que se seńalarían», el Atlas Geográfico de del Perú de Mariano Felipe Paz Soldán apareció en Paris en 1865 y el Mapa Mural del Perú de 1862 fue premiado por la Exposición Internacional de Paris, por su parte Mateo Paz Soldán, hermano menor de Mariano, con apoyo del estado, publica Geografía del Perú en 1862. En lo que respecta a las entidades bancarias, aparece el banco «La Providencia» (1862) con un capital de 500000 pesos, el «Banco

2 Las cartas fueron impresas en 1853 con el título El señor don Domingo Elías a la faz de sus compatriotas. Valparaíso: Imprenta del Mercurio. La llamada "consolidación de la deuda" es uno de los casos de corrupción mejor documentados de la historia nacional. Entre otras fuentes puede consultarse con mucho provecho de Alfonso Quiroz (2013) Historia de la corrupción en el Perú. Lima: IEP, pp.169-189. 
del Perú» (1863) con un capital de 10000000 de pesos, y el «Banco de Lima (1869) con un capital de 3200000 soles. Para la década de 1860, aparecieron los primeros bancos privados extranjeros especializados en el crédito al comercio ultramarino y en la remesa de fondos entre Hispanoamérica y Europa, de los cuales destacaba el banco británico «Banco de Londres, México y Sudamérica» cuya hegemonía en Hispanoamérica se mantuvo en forma exclusivo hasta 1880. El principal objetivo de estos bancos se concentraba en facilitar préstamos al Estado. En palabras de Miriam Salas, el diseño del presupuesto revela que, desde 1845 a 1878, la explotación del guano sostuvo la economía del país (p. 44) por ello existió mayor regularidad en la promulgación de los presupuestos nacionales y las cuentas estatales, sobre todo por la especialización de las funciones del Ministerio de Hacienda. En junio de 1863 durante el corto período de gobierno Pedro Diez Canseco se promulgó el presupuesto 1863-1864. En 1867 los ingresos, según las cuentas levantadas en el Ministerio de Hacienda, continuaron creciendo hasta alcanzar los 22246410 de soles y en paralelo con la misma rapidez los hicieron los egresos al llegar al 26534241.

El período 1869-1972, se encuentra por un lado afrontando las consecuencias del terremoto del 13 de agosto de 1868 y una crisis económica anunciada por el Ministerio de Hacienda tras el endeudamiento y la mala gestión de los recursos provenientes del guano. Los empréstitos se incrementaron en el período 1870-1872 para afrontar la crisis. La aprobación del presupuesto del período 1871-1872, no llegó a aprobarse debido a las fuertes irregularidades que generaba al Congreso las clausulas del contrato Dreyfus. Por tal motivo el Ministerio de Hacienda se vio forzado a mandar abrir a los diversos Ministerios de Estado un crédito mensual por la cantidad de 2457618 soles 40 centavos que al año sumaban 29491 420, 80, que al bienio ascendían a 58982 841, 60 soles. Los ministerios por aquel entonces estaban conformados por: el Ministerio de Relaciones Exteriores, el Ministerio de Gobierno, Policía y obras Públicas, el Ministerio Justicia, Instrucción y Beneficencia, el Ministerio de Guerra y Marina, y el Ministerio de Hacienda y Comercio. Los bancos incrementaron su presencia en la escena política nacional. Entre 1860 y 1875, 17 casas bancarias abrieron sus puertas. La casa Dreyfus abrió un banco con el Estado como accionista. Justificando esta decisión de la siguiente manera: "por el ensanche de la actividad industrial el establecimiento de un nuevo banco y las ventajas que puede obtener el Estado tomando participación, en él mucho más si se atiende al provecho que hoy producen los bancos de emisión y descuento ya establecidos, ha resuelto de acuerdo con el nombre de Banco Nacional del Perú» (p. 79). La información contenida en el presupuesto de 1873-1874 no es del todo exacta para dar cuenta de todos los préstamos asumidos por el Estado para cubrir el déficit fiscal al término de este período. Durante el gobierno de Balta no cesaron las exigencias del Estado por préstamos a los bancos. 
El período 1872-1876, coincide con el gobierno de Pardo, con una mayor presencia de los civilistas en la gestión de las finanzas públicas y la negociación de la deuda con la casa Dreysfus. Pardo ya en la presidencia encara la grave crisis financiera, retrató su gravísimo estado en su informe de Hacienda, presentado el 21 de setiembre de 1872. Hacia julio de 1872 el Perú tenía una deuda de 36800000 de libras esterlinas que en soles, ascendía a 184000000 y que exigía una amortización anual de 1300000 de soles. Por lo que Pardo decidió la descentralización hacendaria, así como desempolvarse una ley de timbres del 11 de febrero de 1869, la que establecía que no admitía a juicio ningún documento sin timbre. Pese a la oposición hacia los contratos con Dreyfus, que el civilismo mostró en años anteriores, Pardo ya en el poder firmó un nuevo empréstito con la casa Dreyfus, lo cual consolidó una nueva deuda interna consolidada el 12 de marzo de 1873 votada por el Gobierno y el Poder Legislativo. Era una medida para poder afrontar el serio problema fiscal por el que atravesaba el país. Sin embargo, la cuenta nacional construida tras las medidas de Pardo, que destaca Salas señalan que: «el presupuesto seguía sin estructurarse bien y muchas veces se calculaba un menor gasto al real o los ingresos se gastaban sin tener en cuenta que debían dura todo el año» (p. 99), parte del problema era que el presupuesto se diseñaba de manera bianual. La revisión y análisis del presupuesto realizada por Salas reveló que en realidad fue de 4215 615, 15 soles anuales y no de 7177 436,95 soles al ańo como se muestra en detalle en el balance general del presupuesto aprobado por el Congreso y por el Presidente de la República Manuel Pardo el 28 de abril de 1873. La situación se tornó más tensa en 1874, ya que pese al diseño presupuestal, la deuda seguía sin disminuir. La ley orgánica de presupuesto del 16 de setiembre de 1874, sentó las bases de lo que sería un cambio positivo en la historia de la administración pública las cuales se plasman, en el diseño de un Presupuesto General de la República se debía dividir en dos: uno ordinario para rentas y gastos permanentes, y otro extraordinario para rentas y desembolsos transitorios ( $\mathrm{p}$. 121). Finalmente, la falta de capacidad de gestión dio como resultado la bancarrota de 1876, el análisis de las cuentas presupuestales le permiten a Salas cuestionar un punto común de la historiografía republicana, representada principalmente por Carmen Mc Evoy, «que presentan a la figura de Pardo como mejor presidente del Perú», el «análisis económico de la y del entorno social» develan una imagen opuesta, y muestran los graves problemas de "gestión de lo público» que atravesó su mandato y los conflictos de intereses presentes en la consolidación de la deuda y las medidas tomadas para afrontar el «déficit fiscal» (p. 157).

El período 1876-1878, afronta el fin de la "falsa bonanza» y la presencia de una red corruptela instalada en las esferas de poder conocida como la argolla o el «argollismo» (término usado por Salas) para explicar la captura de las instituciones públicas por un grupo de personas unidas entre sí por vínculos de parentesco, amistad y relaciones clientelares, además la situación económica se agravó por la emisión de billetes sin valor. En 
materia de presupuesto se llegó a usar «un presupuesto paralelo conocido o bautizado con el nombre de Presupuesto Intruso o Cuentas ajenas al presupuesto que creaban un verdadero desorden fiscal». Mariano Ignacio Prado con la firma del contrato Raphael, para cubrir las deudas del Estado, sin embargo la casa Dreyfus no pudo cubrir sus obligaciones asumidas y se entró en una crisis fiscal. El presupuesto de 1877-1878, muestra "que no siempre el presupuesto se realizaba", principalmente por la poca capacidad estatal para la recaudación. El presupuesto como herramienta administrativa, mejoró notablemente registrando mucho mejor el presupuesto ordinario, los ingresos obtenidos por parte del Estado y a través de sus instituciones. Los gastos por su parte eran mejor descritos a través de una estructura general por pliegos de egreso, gasto e inversión.

La segunda parte del texto la dedica a un análisis formal y social de las diferentes instituciones que intervienen en la creación y aprobación del presupuesto 1879-1880. El Ministerio de Hacienda, El Congreso, y el Ejecutivo, son analizados como los entes responsables de diseñar el Presupuesto General de la República. La asignación presupuestal a los diferentes ministerios divididos en sus dos partes: Presupuesto Ordinario y Presupuesto Extraordinario, analizados con rigurosidad dan un panorama más completo del perfeccionamiento de las herramientas administrativas previas a la Guerra con Chile.

El texto, es un aporte enorme a la historia institucional de nuestro país, tanto por las fuentes utilizadas como por el análisis puntual ligado a la gestión y evolución del Estado, generalmente obviados por los historiadores por el énfasis en la historia social. La obra de Miriam Salas es un aporte importantísimo, pues con mucho talento nos ofrece un panorama amplio de las diversas dimensiones del presupuesto: político, administrativo, institucional y social. Por lo que no es un texto que se agota en un recuento de normas y cuadros estadísticos, sino que contribuye a dar una lectura política y social de las herramientas e instrumentos administrativos que emplea el Estado para mejorar su funcionamiento y asegurar su supervivencia. Los temas que aborda no pueden ser más pertinentes en el contexto del bicentenario. Sobre todo lo referente a la capacidad de gestión del Estado, el perfeccionamiento de las instituciones y la burocracia, y el tan actual tema, de la corrupción en el seno del Estado. Temas relevantes que nos obligan a profundizar e investigar aún más en las dinámicas internas del Estado y sus instituciones. 